\title{
Reflex Cardioventilatory Responses to Hypoxia in the Flathead Gray Mullet (Mugil cephalus) and Their Behavioral Modulation by Perceived Threat of Predation and Water Turbidity ${ }^{\star}$
}

\author{
A. Shingles ${ }^{1, \dagger}$ \\ D. J. McKenzie ${ }^{2, *}$ \\ G. Claireaux ${ }^{2, \$}$ \\ P. Domenici ${ }^{1,3, \|}$ \\ ${ }^{1}$ International Marine Centre, Località Sa Mardini, 09072 \\ Torregrande (Or), Italy; ${ }^{2}$ Centre de Recherche sur les \\ Écosystèmes Marins et Aquacoles, Centre National de la \\ Recherche Scientifique-IFREMER, Place Du Séminaire, BP 5, \\ 17137, L'houmeau, France; ${ }^{3}$ Consiglio Nazionale delle \\ Ricerche, Istituto per l'Ambiente Marino e Costiero, Località \\ Sa Mardini, 09072 Torregrande (Or), Italy
}

Accepted 10/5/2004; Electronically Published 7/28/2005

\begin{abstract}
In hypoxia, gray mullet surface to ventilate well-oxygenated water in contact with air, an adaptive response known as aquatic surface respiration (ASR). Reflex control of ASR and its behavioral modulation by perceived threat of aerial predation and turbid water were studied on mullet in a partly sheltered aquarium with free surface access. Injections of sodium cyanide $(\mathrm{NaCN})$ into either the bloodstream (internal) or ventilatory water stream (external) revealed that ASR, hypoxic bradycardia, and branchial hyperventilation were stimulated by chemoreceptors sensitive to both systemic and water $\mathrm{O}_{2}$ levels. Sight of a model avian predator elicited bradycardia and hypoventilation, a fear response that inhibited reflex hyperventilation following external $\mathrm{NaCN}$. The time lag to initiation of ASR following $\mathrm{NaCN}$ increased, but response intensity (number of events, time at the surface) was unchanged. Mullet, however, \footnotetext{
of Behaviour and Physiology," which took place at the Society for Experimental Biology annual meeting, Heriot-Watt University, Edinburgh, Scotland, March 29-April 2, 2004.

†E-mail: alexandrashingles@yahoo.co.uk.

${ }^{\ddagger}$ Current address: Department of Marine Ecology and Aquaculture, Danish Institute for Marine Research, North Sea Centre, DK-9850 Hirtshals, Denmark; e-mail:dmc@dfu.min.dk.

${ }^{\S}$ E-mail: guy.claireaux@ifremer.fr.
}

* This article is based on a presentation given in the symposium "Integration

"E-mail: p.domenici@imc-it.org, paolo.domenici@iamc.cnr.it.
\end{abstract}

Physiological and Biochemical Zoology 78(5):744-755. 2005. (C) 2005 by The University of Chicago. All rights reserved. 1522-2152/2005/7805-4056\$15.00 modified their behavior to surface under shelter or near the aquarium edges. Turbid water abolished the fear response and effects of the predator on gill ventilation and timing of ASR following external $\mathrm{NaCN}$, presumably because of reduced visibility. However, in turbidity, mullet consistently performed ASR under shelter or near the aquarium edges. These adaptive modulations of ASR behavior would allow mullet to retain advantages of the chemoreflex when threatened by avian predators or when unable to perceive potential threats in turbidity.

\section{Introduction}

The flathead gray mullet is a euryhaline teleost that inhabits tropical and subtropical coastal waters, lagoons, and estuaries throughout the world. These habitats are prone to hypoxia (Diaz 2001), and in mullet this has been reported to elicit a behavior known as aquatic surface respiration (ASR; Dickson Hoese 1985). This is an adaptive response that is common among teleosts that inhabit hypoxic environments, whereby they rise to the surface to ventilate the well-oxygenated layer of water in contact with air (Kramer and McClure 1982; Dickson Hoese 1985). The response presumably evolved because it provided selective advantages in the colonization of hypoxic habitats (Lewis 1970; Gee et al. 1978; Kramer and McClure 1982), and it is believed to have been one of the evolutionary precursors of true air breathing in ancestral fishes and, hence, in all vertebrates (Randall et al. 1981). In the vertebrates, adaptive changes in cardiac and ventilatory activity in response to hypoxia are nervous reflexes stimulated by peripheral $\mathrm{O}_{2}$ sensitive chemoreceptors (Smatresk 1990). In typical waterbreathing teleosts, these receptors are sensitive to water and blood $\mathrm{O}_{2}$ levels and stimulate a profound bradycardia coupled with an increase in gill ventilation (Burleson and Smatresk $1990 a, 1990 b$; Burleson et al. 1992). Similar receptors stimulate the complex surfacing and air-gulping behaviors exhibited in hypoxia by fish with air-breathing organs and bimodal respiration (Smatresk et al. 1986; McKenzie et al. 1991; Taylor et al. 1996). Despite the widespread occurrence of ASR in the teleosts (Kramer and McClure 1982), very little is known about the role of chemoreceptors in stimulating the surfacing behavior (Florindo et al. 2002, 2004).

Although ASR and air breathing are presumed to have 
evolved because they provided selective advantages in hypoxic habitats, both laboratory and field studies have demonstrated that surfacing can expose fish to significantly increased risks of predation by birds (Kramer et al. 1983; Kersten et al. 1991). The potential interactions between $\mathrm{O}_{2}$ chemoreflexes and responses to threat of predation have been studied very little in fish. In water-breathing fish, threat of predation (exposure to a model predator) can cause bradycardia and hypoventilation (Johnsson et al. 2001; Cooke et al. 2003), but how this might modulate $\mathrm{O}_{2}$ chemoreflexes is not known. When fish with bimodal respiration perceive a threat of aerial predation in hypoxia, they reduce air-breathing frequency (Smith and Kramer 1986; Herbert and Wells 2001) and compensate by increased reliance on gill ventilation (Smith and Kramer 1986) or reduced rates of activity (Herbert and Wells 2001). This is evidence that higher processing can influence reflexive air-breathing behavior, with adaptive responses that would allow the fish to conserve the $\mathrm{O}_{2}$ stored in their air-breathing organs. Such compensatory strategies are not available to fish that perform ASR because they cannot store atmospheric air (Kramer and McClure 1982). There is, however, some evidence of modulation of ASR behaviors in the laboratory (Kramer et al. 1983), and in the field, it has been reported that fish performing ASR may move to the water's edge to take shelter under riparian vegetation when threatened by aerial predation (Kersten et al. 1991). Investigating how the threat of predation influences ASR responses would demonstrate whether the mullet have evolved the ability to modulate behavioral components of the chemoreflex and thereby retain the advantages of ASR while mitigating the risks of predation.

As well as being hypoxic, the coastal lagoons and estuaries inhabited by mullet are often extremely turbid environments. Turbidity is known to exert powerful modulatory effects on predatory interactions through effects on visual perception by both predator and prey (Gregory 1988, 1993; Gregory and Northcote 1993). In particular, it might be assumed that turbidity would increase the risk of aerial predation for mullet in hypoxia if surfacing fish were unable to perceive and avoid the threat. If, however, turbidity were a consistent factor in their environment, the mullet may have evolved compensatory behavioral strategies that allow them to minimize the risk of aerial predation while performing ASR. The potential effects of turbidity on responses to hypoxia, particularly ASR behavior and other $\mathrm{O}_{2}$ chemoreflexes, have, however, never been investigated.

This study described reflex cardiac, branchial, and ASR responses to hypoxia in the mullet and investigated the role of $\mathrm{O}_{2}$ chemoreceptors in these reflexes by stimulation with sodium cyanide $(\mathrm{NaCN})$. The effects of a perceived threat of predation on such reflex responses and how this, in turn, was influenced by water turbidity were then investigated. We explored the hypothesis that mullet would exhibit adaptive modulation of behavioral elements in the ASR chemoreflex in order to retain its advantages while mitigating the threat of aerial predation.
It was predicted that such adaptive modulation would be revealed as selecting to perform ASR under shelter and near vertical edges when threatened by a predator or in turbid water.

\section{Methods}

\section{Experimental Animals}

Flathead gray mullet (Mugil cephalus L.) with a mean ( $\pm \mathrm{SE}$ ) mass of $565 \pm 38 \mathrm{~g}$ were caught from a local brackish water lagoon (Cabras, Province of Oristano, Sardinia) and transported to the International Marine Centre. They were maintained indoors in a circular tank (2-m diameter, water volume approximately $3,000 \mathrm{~L}$ ) in seawater at a salinity of $36.2 \%$ o \pm $0.2 \%$ and temperature of $24.5^{\circ} \pm 0.3^{\circ} \mathrm{C}$ under a natural photoperiod for at least $2 \mathrm{wk}$ before experimentation. Mullet were fed a commercial pelleted feed once daily but starved for at least $24 \mathrm{~h}$ before use in experiments.

\section{Surgical Preparation}

Fish were anesthetized under $0.2 \mathrm{~g} \mathrm{~L}^{-1}$ tricaine methane sulphonate (MS-222) in seawater and then transferred to an operating table, where their gills were irrigated with aerated seawater containing MS-222 at $0.05 \mathrm{~g} \mathrm{~L}^{-1}$. A cannula (PE50, Intramedic) was implanted in the afferent branchial artery at the base of a third gill arch using the technique described by McKenzie et al. (1999), with the cannula being advanced down the artery until the tip protruded into the ventral aorta. A buccal cannula (PE50) was fitted in the lower lip, as described by McKenzie and Taylor (1996). A third cannula (PE90 Intramedic) was fitted to the operculum, as described by McKenzie et al. (1995). Fish were recovered for at least $24 \mathrm{~h}$ in aerated biofiltered seawater before use in any experiments.

\section{Experimental Setup}

Following their recovery from surgery, individual fish were transferred to a chamber constructed of glass and Perspex (69 $\mathrm{cm}$ long $\times 16 \mathrm{~cm}$ wide $\times 50 \mathrm{~cm}$ high) in water at a depth of $28 \mathrm{~cm}$, with free access to the water surface. A sheltered area (20 $\mathrm{cm}$ long $\times 16 \mathrm{~cm}$ wide, made of opaque plexiglass) was provided at the rear of the aquarium. The shelter did not obstruct surface access (positioned $12 \mathrm{~cm}$ above the water surface). All fish were left to acclimate to this chamber for at least $12 \mathrm{~h}$ (overnight) before initiating experiments. Seawater circulated through the chamber, a biofilter, a thermostatted cooler, and then a large gas exchange column before returning to the chamber at a constant rate of approximately $20 \mathrm{~L} \mathrm{~min}^{-1}$. Total water volume was approximately $100 \mathrm{~L}$, and water temperature was maintained at $25^{\circ} \mathrm{C}$ for all experiments. Screens isolated the chamber on three sides to avoid disturbance of the fish by experimenters. A 500-W halogen spotlight positioned $2 \mathrm{~m} \mathrm{di}$ agonally above and to the front of the open fourth side of the 
chamber illuminated the fish. A CCD camera filmed the chamber diagonally from the front at about $1 \mathrm{~m}$ away and $60 \mathrm{~cm}$ above the water surface (i.e., below and in front of the light source). Thus, the fish was visible both within the water column from the side of the chamber and through/at the water surface within the chamber. The images were displayed on a monitor and recorded onto videotapes. All cannulae were long enough to extend above the fish through a small hole in the screens and to the outside, where they could be manipulated without disturbing the animal, and they did not restrict its movements in the chamber.

The saline-filled arterial cannula was attached to a physiological pressure transducer (Statham P23XL), and the waterfilled opercular cannula was attached to a differential pressure transducer (Validyne 45DF). The signals from these transducers were amplified (Gould Universal and Carrier amplifiers, respectively) and then acquired and displayed real time on a PC via a USB data acquisition system and related software (Iotech Personal Daq 56). The transducers were calibrated against columns of water to acquire measurements of heart rate $\left(f_{\mathrm{H}}\right.$, beats $\left.\min ^{-1}\right)$ and ventral aortic blood pressure $\left(\mathrm{P}_{\mathrm{VA}}, \mathrm{kPA}\right)$ from the arterial cannula; ventilation rate $\left(f_{\mathrm{G}}\right.$, beats $\left.\mathrm{min}^{-1}\right)$ and opercular pressure amplitude $\left(\mathrm{P}_{\mathrm{OP}}, \mathrm{Pa}\right.$, an index of ventilatory effort $)$ from the opercular cannula. ASR episodes were visible on the monitor and also evident as large pressure excursions on the opercular trace. No experiments were initiated until cardiac and branchial ventilatory variables had remained stable for $30 \mathrm{~min}$.

\section{Experimental Protocol}

Cardiac, branchial, and ASR responses to the following treatments were investigated, with the treatments given in random order.

Aquatic Hypoxia. Fish were exposed to stepwise reductions in $\mathrm{Po}_{2}$ from $40 \%, 20 \%$, and $10 \%$ air saturation (8.4, 4.2, and 2.1 $\mathrm{kPa}$, respectively), with the transition period between $\mathrm{Po}_{2}$ levels lasting $15 \mathrm{~min}$ and each level of hypoxic $\mathrm{Po}_{2}$ maintained for 15 min. Hypoxia was generated by passing a flow of $100 \% \mathrm{~N}_{2}$ through the gas exchange column.

Internal $\mathrm{NaCN}$. Three hundred micrograms of $\mathrm{NaCN}$ dissolved in $300 \mu \mathrm{L}$ of saline was delivered as a bolus injection via the afferent branchial cannula. Sham injections were performed with $300 \mu \mathrm{L}$ of the saline vehicle alone. During these arterial injections, blood pressure recordings were temporarily discontinued by closure of a three-way stopcock at the pressure transducer.

External NaCN. Two milligrams of $\mathrm{NaCN}$ dissolved in $2 \mathrm{~mL}$ saline was given as a bolus injection into the buccal cavity via the buccal cannula. Sham injections were performed with 2 $\mathrm{mL}$ of the saline vehicle alone.
External NaCN with a Model Predator. The avian predator was a life-sized polystyrene model of a generalized aerial bird predator in full flight. The "bird" was attached to a long steel wire and passed over the chamber in front of the spotlight so that its shadow passed over the fish. The model was passed over once every $6 \mathrm{~s}$, beginning $30 \mathrm{~s}$ before an external $\mathrm{NaCN}$ injection was given as described above.

Animals were allowed at least 30 min recovery from $\mathrm{NaCN}$ injections and $4 \mathrm{~h}$ recovery from hypoxia. These experiments were then repeated on a separate group of six mullet maintained in water at a turbidity of 300 nephelometric turbidity units (NTU), created by adding Polsperse 10 Kaolin to the seawater in the recirculating system. Polsperse 10 kaolin is a fine-grade pulverized kaolin with a relatively flat wavelength absorbance curve and a low settling speed. The biofilter was detached for these experiments, with seawater in the system completely replaced after each fish studied. During turbidity treatments, the position of the fish was assumed to be central if the fish was not visible at the edges of the aquarium when deeper in the water column. The location of fish was evident when performing ASR. This degree of turbidity is within the higher part of the range measured in the local Cabras lagoon.

\section{Uncannulated Animals}

To investigate the effects of the model predator on ASR in hypoxia, a group of uncannulated fish were acclimated overnight to the same water conditions as described above and then exposed to stepwise reductions in $\mathrm{Po}_{2}$ from normoxia to $40 \%$, $20 \%, 10 \%$, and $5 \%$ air saturation, with each level of hypoxia maintained for $15 \mathrm{~min}$. Experiments were repeated twice, with an overnight recovery between each hypoxic exposure. The model bird predator was passed overhead every $6 \mathrm{~s}$ at each level of hypoxia, conducted randomly on either day 1 or day 2. These experiments were then repeated on fish in turbid water.

\section{Data Analysis}

Heart rate, $\mathrm{P}_{\mathrm{VA}}, \mathrm{P}_{\mathrm{OP}}$, and $f_{\mathrm{G}}$ were measured for $60 \mathrm{~s}$ in normoxia and after $10 \mathrm{~min}$ exposure to each level of hypoxia. At each water $\mathrm{Po}_{2}$, the proportion of fish performing ASR, the surfacing frequency, and the length of each ASR event were calculated. The cardiac and branchial variables were measured for $30 \mathrm{~s}$ before each $\mathrm{NaCN}$ (or sham) injection (considered "control" value) and for $15 \mathrm{~min}$ following. The "peak response" was identified from the pressure traces, and the mean $( \pm S E)$ lag to peak response was calculated (McKenzie et al. 1995). The variables were counted for $30 \mathrm{~s}$ of the peak response, and the factor of change at peak response relative to the control value was calculated. The lag to the first ASR response was calculated, and the mean $( \pm S E)$ number and the total duration of ASR events were measured for 15 min after each $\mathrm{NaCN}$ (or sham) injection. The locations of ASR events for each fish were com- 
a)

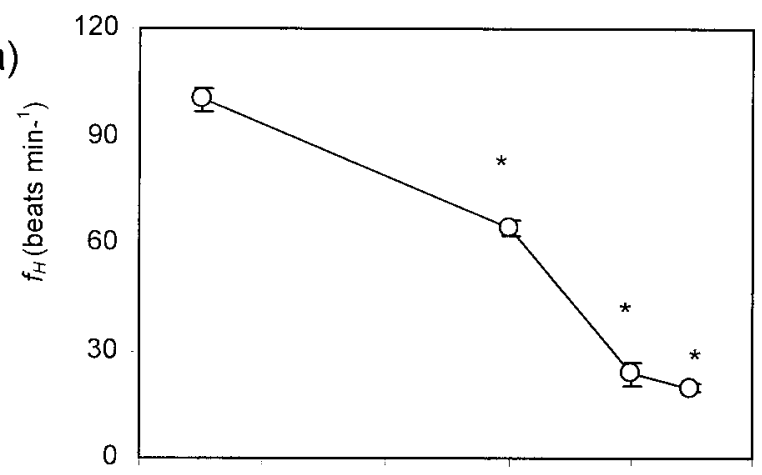

b)
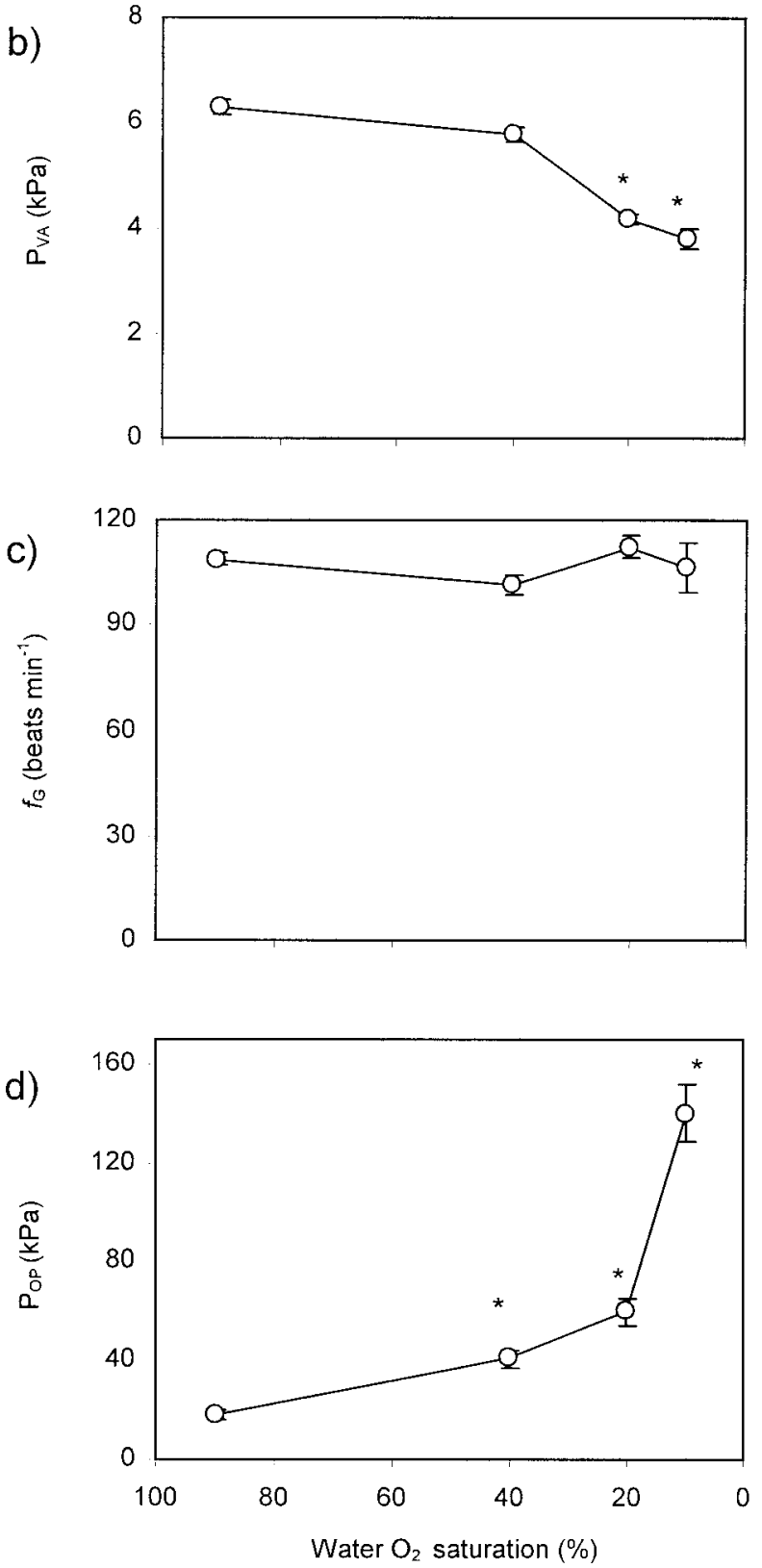

pared between treatments with regard to the proportion of fish performing ASR under shelter and the distance between the ASR location and the nearest wall. When all ASR events were considered, the average distance from the ASR location to the nearest wall was calculated for each fish under each treatment. These average values were subsequently compared. Variables were compared between internal and external $\mathrm{NaCN}$ treatments and between external $\mathrm{NaCN}$ treatments with and without the model predator by multifactorial ANOVA (unless otherwise stated in the text). Variables were compared between clear and turbid treatments with and without the model predator by using a Type III nested ANOVA (unless otherwise stated in the text). Post hoc analysis was conducted using a Tukey test. In some cases, a paired $t$-test was used to compare two variables as an independent contrast, as stated in the text. Results were considered to be significant at the $95 \%$ level of confidence, when $P<0.05$.

\section{Results}

Responses to Hypoxia and the Role of $\mathrm{O}_{2}$ Chemoreceptors

In normoxic water, once recovered fully from surgery, the mullet tended to occupy the center of the chamber, often sitting at an intermediate height in the water column, facing the water flow and maintaining position with gentle sculling movements of the pectoral fins. Hypoxia caused a progressive bradycardia and decline in $\mathrm{P}_{\mathrm{VA}}$, no significant stimulation of $f_{\mathrm{G}}$, but a pronounced increase in $\mathrm{P}_{\mathrm{OP}}$ (Fig. 1). ASR initiated as water $\mathrm{O}_{2}$ saturation fell below $20 \%$ and was performed by all fish at $10 \%$ saturation. The response consisted of rising repeatedly to the water surface such that the upper lip and snout emerged. Fish remained at the surface for a period ranging between 2 and 11 $s$ before returning to the bottom of the chamber, often releasing small bubbles from the opercula as they descended.

As shown in Table 1, both internal and external $\mathrm{NaCN}$ elicited a profound bradycardia and drop in $\mathrm{P}_{\mathrm{VA}}$, an increase in $f_{\mathrm{G}}$, and a marked increase in $\mathrm{P}_{\mathrm{OP}}$. The cardiac response was almost instantaneous: the heart rate dropped and $\mathrm{P}_{\mathrm{VA}}$ dropped precipitously, such that the peak response occurred over the first heartbeat following the $\mathrm{NaCN}$; the mean lag denotes the average length of this bradycardic beat. Heart rate and $\mathrm{P}_{\mathrm{VA}}$ then returned quite rapidly toward control values within the ensuing $5 \mathrm{~min}$. The ventilatory responses occurred more gradually, rising to a maximum within fewer than $30 \mathrm{~s}$ following the $\mathrm{NaCN}$ and then returning toward control over the ensuing $5 \mathrm{~min}$. The time lags to peak cardiac responses were similar for internal and external

Figure 1. Effect of stepwise reductions in water $\mathrm{Po}_{2}$ on mean $( \pm \mathrm{SE})$ heart rate $(a)$, blood pressure $(b)$, ventilatory frequency $(c)$, and opercular pressure amplitude $(d)$ of Mugil cephalus in water at a temperature of $25^{\circ} \mathrm{C}$ and salinity of $36 \%$. Asterisks denote a significant difference from normoxic values for that variable. 
Table 1: Mean $( \pm$ SE) cardiac and gill ventilatory variables in Mugil cephalus and time lags to peak responses

\begin{tabular}{lrlcl}
\hline & $f_{\mathrm{H}}\left(\right.$ beats $\left.\mathrm{min}^{-1}\right)$ & $\mathrm{P}_{\mathrm{VA}}(\mathrm{kPa})$ & $f_{\mathrm{G}}$ (beats $\left.\mathrm{min}^{-1}\right)$ & $\mathrm{P}_{\mathrm{OP}}(\mathrm{Pa})$ \\
\hline External NaCN: & & & & \\
$\quad$ Control & $101.7 \pm 1.9$ & $6.6 \pm .1$ & $103.1 \pm 2.7$ & $22.6 \pm 2.7$ \\
$\quad$ Response & $12.9 \pm 1.1^{\star}$ & $3.2 \pm .2^{\star}$ & $129.4 \pm 3.8^{\star}$ & $85.7 \pm 7.9^{\star}$ \\
$\quad$ Time lag (s) & $8.3 \pm .7^{\mathrm{A}}$ & $8.3 \pm .7^{\mathrm{A}}$ & $21.9 \pm .7^{\mathrm{B}}$ & $21.9 \pm .7^{\mathrm{B}}$ \\
Internal NaCN: & & & & \\
$\quad$ Control & $96.9 \pm 1.2$ & $6.5 \pm .1$ & $107.3 \pm 4.6$ & $16.6 \pm 2.1$ \\
$\quad$ Response & $5.1 \pm .2^{\star}$ & $1.2 \pm .2^{\star}$ & $144.6 \pm 4.4$ & $66.3 \pm 7.8^{\star}$ \\
$\quad$ Time lag (s) & $7.9 \pm .7^{\mathrm{A}}$ & $7.9 \pm .7^{\mathrm{A}}$ & $13.7 \pm .4^{\mathrm{C}}$ & $13.7 \pm .4^{\mathrm{C}}$ \\
\hline
\end{tabular}

Note. Data are either before (control) or at peak response (response) following a bolus of $2 \mathrm{mg} \mathrm{NaCN}$ into the ventilatory stream via a buccal cannula (external $\mathrm{NaCN}$ ) or a bolus of $300 \mu$ g sodium cyanide $(\mathrm{NaCN})$ into the afferent branchial artery (internal $\mathrm{NaCN}$ ). In all cases, $n=7 ; f_{\mathrm{H}}$, heart rate; $\mathrm{P}_{\mathrm{VA}}$, ventral aortic blood pressure; $f_{G}$, ventilatory frequency; $\mathrm{P}_{\mathrm{OP}}$, opercular pressure amplitude. Where indicated, a different letter indicates a significant difference between the means for that variable.

* Denotes a significant difference between control and response values for that variable.

$\mathrm{NaCN}$, whereas the lag to the peak branchial response was significantly shorter following internal $\mathrm{NaCN}$. Both internal and external $\mathrm{NaCN}$ stimulated ASR (Table 2), with no significant differences in the lag to first response, the numbers of ASR events, and time at the surface.

\section{Modulatory Effect of the Model Predator on $\mathrm{O}_{2}$ Chemoreflexes}

Exposure of the mullet to the shadow of the model predator caused them to drop to the bottom of the tank and reduce their pectoral sculling movements. The model predator never caused the fish to become visibly agitated or search around the sides of the chamber attempting to escape. Figure 2 shows the effects on cardiac and branchial variables of the model predator and how this then influenced responses to $\mathrm{NaCN}$. The data collected for responses to external $\mathrm{NaCN}$ without the predator (Table 1) are shown in Figure 2 in order to permit a direct comparison with any effects elicited by the model predator. Exposure of the fish to the model caused a significant bradycardia and reduction in $f_{\mathrm{G}}$ but was without effect on $\mathrm{P}_{\mathrm{VA}}$ and $\mathrm{P}_{\mathrm{OP}}$ (Fig. 2).

The model predator had significant modulatory effects on reflex responses to $\mathrm{NaCN}$. Although the cardiac response was almost instantaneous, the first beat was not the peak response, as observed without the predator (see above), but rather the heart slowed more gradually such that the lowest $f_{\mathrm{H}}$ and $\mathrm{P}_{\mathrm{VA}}$ occurred over the second heartbeat, and the cardiac variables then gradually returned toward normal over the ensuing $5 \mathrm{~min}$. As shown in Figure 2, the model predator caused the peak response bradycardia to be significantly greater than the peak response in the absence of a predator, and it also significantly increased the time lag to peak cardiac response from $8.3 \pm$ 0.7 (external NaCN; Table 1 ) to $14.7 \pm 0.8 \mathrm{~s}$. The model predator had severe inhibitory effects on the branchial reflex re- sponse. It abolished the reflex increase in $f_{\mathrm{G}}$ and significantly reduced the peak increase in $\mathrm{P}_{\mathrm{OP}}$ (Fig. 2). The development of the modest opercular pressure response was also slowed significantly, the time lag to peak ventilatory response increased from $21.9 \pm 0.7$ (external $\mathrm{NaCN}$; Table 1$)$ to $67.1 \pm 4.9 \mathrm{~s}$, and the response had disappeared completely by $5 \mathrm{~min}$ following the injection.

As shown in Figure 3, the presence of the model predator also increased the time lag to the onset of ASR. To permit comparison, this figure also carries the data for external $\mathrm{NaCN}$ without the model predator reported in Table 2 . The presence of the model did not reduce the proportion of fish that performed ASR ( $86 \%$ of fish, both with and without the model predator), and once ASR had begun, the subsequent number of ASR episodes and the total time spent at the surface were the same as observed without the model (Fig. 3). However, in the presence of the model predator, the mullet moved away from the center of the tank floor to perform ASR close to the

Table 2: Mean ( \pm SE) time lag to the onset of aquatic surface respiration (ASR), the total number of ASR episodes, and the total time spent conducting ASR at the surface for Mugil cephalus

\begin{tabular}{lcc}
\hline & External NaCN & Internal NaCN \\
\hline $\begin{array}{l}\text { Time lag to first ASR } \\
\text { episode }(\mathrm{s})\end{array}$ & $33.8 \pm 6.5$ & $110.0 \pm 42.8$ \\
$\begin{array}{l}\text { Total number of ASR } \\
\quad \text { episodes }\end{array}$ & $16.2 \pm 6.7$ & $21.4 \pm 11.0$ \\
Total surface time $(\mathrm{s})$ & $61.3 \pm 16.1$ & $65.1 \pm 32.4$ \\
\hline
\end{tabular}

Note. Data following a bolus of $2 \mathrm{mg} \mathrm{NaCN}$ into the ventilatory stream via a buccal cannula (external $\mathrm{NaCN}$ ) or a bolus of $300 \mu \mathrm{g}$ sodium cyanide $(\mathrm{NaCN})$ into the afferent branchial artery (internal $\mathrm{NaCN})$. In all cases, $n=7$. 

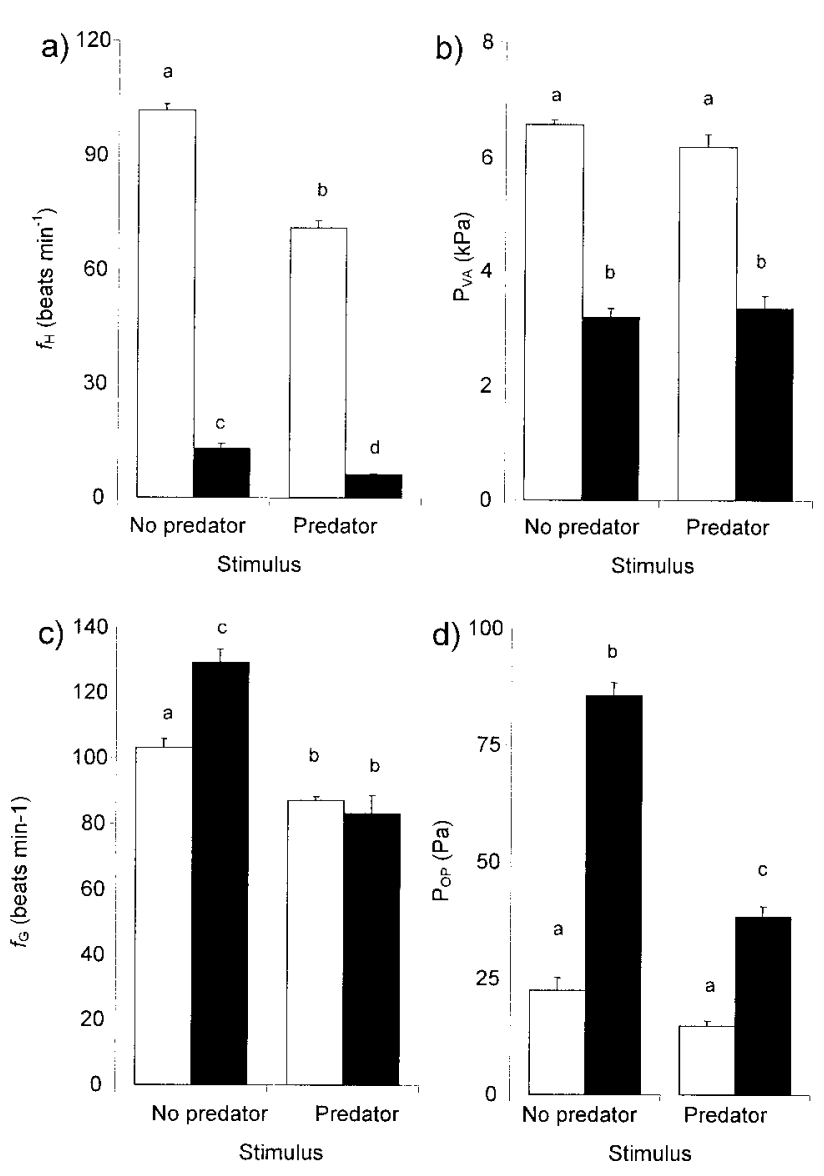

Figure 2. Effect of a model bird predator on mean $( \pm \mathrm{SE})$ heart rate $(a)$, blood pressure $(b)$, ventilatory frequency $(c)$, and opercular pressure amplitude $(d)$ either before (open columns) or at peak response after (solid columns) an external application of $2 \mathrm{mg} \mathrm{NaCN}$ into the ventilatory stream via a buccal cannula in Mugil cephalus in water at a temperature of $25^{\circ} \mathrm{C}$ and salinity of $36 \%$. Where indicated, a different letter indicates a significant difference between the means for that variable.

walls of the aquarium and under the sheltered area at the rear. As a result, ASR occurred significantly closer to the walls and more under the sheltered area by comparison with fish that were not exposed to the model (Fig. 4; Table 3).

\section{Modulatory Effects of Turbidity}

Turbidity did not cause any visible signs of distress in the mullet. They did not move toward the edges of the chamber or attempt to escape but remained almost invisible in the center of the turbid chamber. Turbidity had no significant effects on any cardiac or branchial variable compared with the control normoxic fish in clear water and did not stimulate ASR in normoxia (data not shown). Reflex cardiac and branchial responses to hypoxia, internal $\mathrm{NaCN}$, and external $\mathrm{NaCN}$ did not differ in any respect in turbidity from those measured in clear water.
ASR responses in turbidity also did not differ from responses in clear water following internal and external $\mathrm{NaCN}$. As a result, these data are not shown, with the exception of responses to external NaCN (Figs. 5, 6), which are shown to permit a comparison with the responses to external $\mathrm{NaCN}$ following exposure to the model predator in turbidity. However, even when the predator was absent, in turbid water, the mullet moved away from the center of the chamber to perform ASR near the walls (Table 3; Fig. 4).

The predator did not elicit any bradycardia or hypoventilation in turbid water (Fig. 5). Furthermore, the model predator had no effect on cardiac and branchial responses to $\mathrm{NaCN}$, which were identical to those observed in turbid water without the predator (Fig. 5) and therefore also identical to those observed in clear water without a model predator (cf. Figs. 2, 5). Turbidity also abolished the time delays to peak cardiac and branchial responses elicited by the model predator in clear water; lags to peak response were identical to those observed without a predator (data not shown).

The presence of the model predator in turbidity did not reduce the proportion of fishes that performed ASR in response to external $\mathrm{NaCN}$ (100\% of fish in turbidity compared with $86 \%$ in clear water). Furthermore, the model predator did not elicit any delay in the onset of ASR in turbid water (Fig. 6), and the delay was the same as that observed in clear water without a model predator (cf. Figs. 3, 6). Once ASR had begun, the subsequent number of ASR episodes and the total time spent at the surface did not differ from those observed without the model predator in turbid or clear water (cf. Figs. 3, 6). However, the ASR was performed close to the walls of the aquarium and under shelter at the rear (Fig. 4; Table 3).

\section{Responses to the Threat of Predation in Hypoxia}

The effects of predation risk on ASR in hypoxia were investigated in the noninstrumented fish. In clear water, the predator delayed the onset of ASR such that no fish performed ASR above $5 \%$ air saturation compared with the initiation of ASR at $12.1 \% \pm 3.0 \%$ air saturation in the absence of a predator and $67 \%$ of all fish performing ASR by $10 \%$ air saturation (with an average frequency of $0.3 \pm 0.2$ events $\mathrm{min}^{-1}$, each lasting for $0.7 \pm 0.2 \mathrm{~s}$ ). The predator also reduced the proportion of fish performing ASR at 5\% air saturation to $67 \%$, compared with $100 \%$ in the absence of a predator. The predator had no modulatory effect on the length of each ASR event $(1.4 \pm 0.1$ and $8.8 \pm 4.1 \mathrm{~s}$ in the absence and presence of the model predator, respectively) or the ASR frequency (3.7 \pm 1.0 and $1.9 \pm 0.7$ events $\mathrm{min}^{-1}$ in the absence and presence of the model predator, respectively) at $5 \%$ air saturation. The presence of the model predator did, however, cause ASR to occur more frequently close to the walls of the aquarium (Table 3; Fig. 7).

Turbidity had no effect on ASR responses to hypoxia, which 

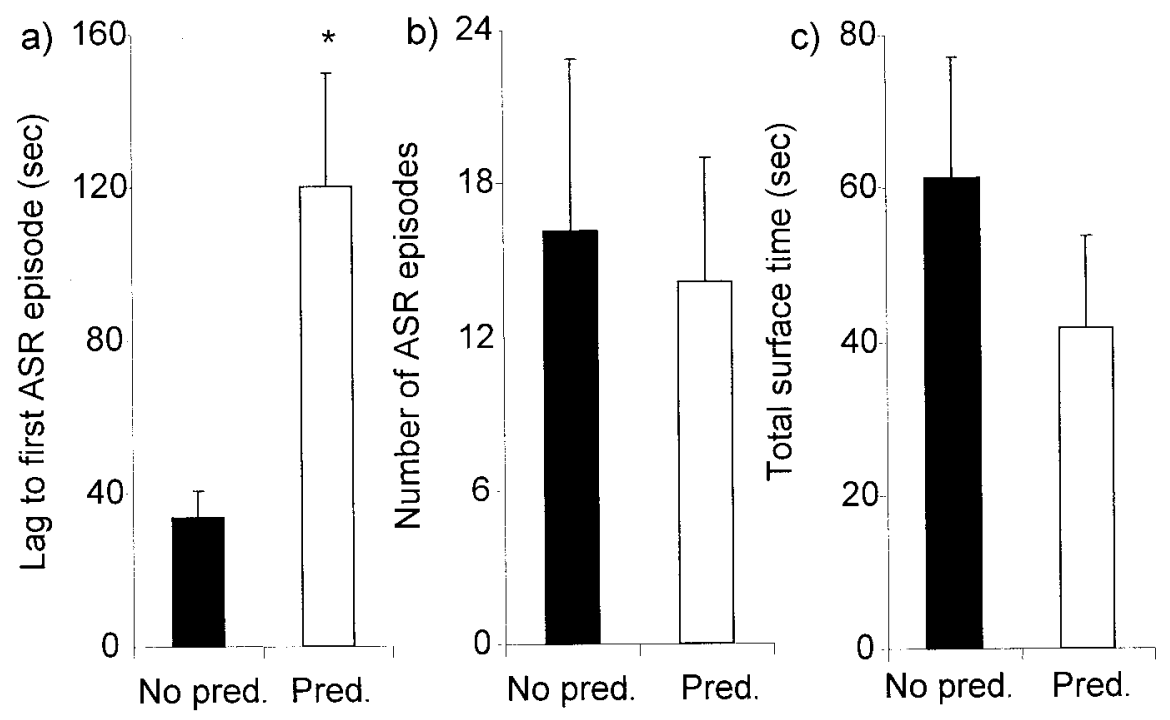

Figure 3. Effect of a model predator on mean $( \pm$ SE) time lag to the onset of aquatic surface respiration (ASR; $a$ ), number of ASR episodes (b), and total time spent at the surface performing ASR (c) following an external application of $2 \mathrm{mg} \mathrm{NaCN}$ into the ventilatory stream via a buccal cannula in Mugil cephalus in water at a temperature of $25^{\circ} \mathrm{C}$ and salinity of $36 \%$. Asterisk denotes a significant difference from values in the absence of a model predator.

started at $12.5 \% \pm 6.1 \%$ air saturation, and had no modulatory effect on the number of ASR episodes $(0.1 \pm 0.0$ and $1.9 \pm$ 0.3 events $\min ^{-1}$ at $10 \%$ and $5 \%$ air saturation, respectively) or the length of each event $(0.3 \pm 0.2$ and $2.0 \pm 1.1 \mathrm{~s}$ at $10 \%$ and $5 \%$ air saturation, respectively) when compared with fish in clear water without a model predator. The model predator did not inhibit ASR behavior in any of the fish exposed to hypoxia in turbid water. However, there was some effect of the predator in that no fish performed ASR until water saturation fell to $5 \%$, whereas all fish performed ASR at $10 \%$ saturation in the absence of the predator. As shown in Table 3 and Figure 7, however, ASR was consistently performed near the aquarium edges in turbidity, regardless of whether the model predator was present (Table 3; Fig. 7).

\section{Discussion}

\section{Responses to Hypoxia and the Role of $\mathrm{O}_{2}$ Chemoreceptors}

The results indicate that mullet exhibit the typical hypoxic reflexes of water-breathing fish, with a bradycardia and increased gill ventilation, and that the ASR response is stimulated only by very low water $\mathrm{O}_{2}$ saturations below 20\%. The behavior whereby the upper lip and snout emerged is believed to allow fish to hold bubbles in the buccal cavity, which may enrich $\mathrm{O}_{2}$ in the ventilatory water to a greater extent than surface ventilation alone and also contribute to lift (Dickson Hoese 1985; Gee and Gee 1991; Chapman et al. 1994). This would explain why the mullet often released small bubbles from their opercula when they ceased ASR and descended back into the water column.

The NaCN applications indicated that these hypoxic reflexes are stimulated by chemoreceptors that are sensitive to both water and blood $\mathrm{O}_{2}$ levels. There is considerable evidence to demonstrate that the gills are the major sites for these peripheral a)

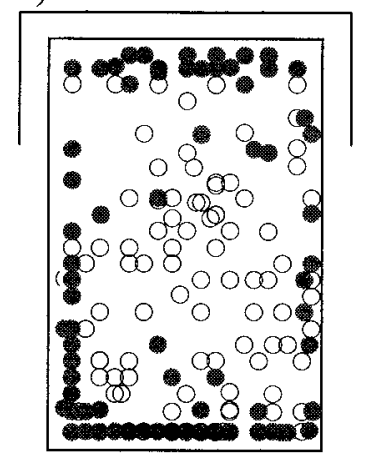

b)

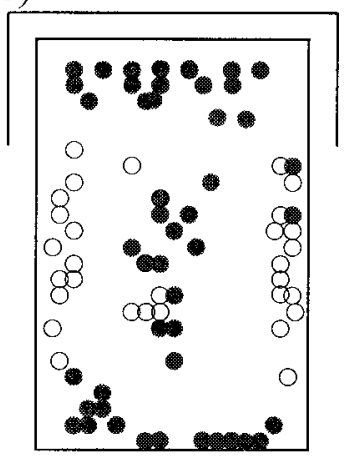

Figure 4. Aerial view of locations of aquatic surface respiration (ASR) events performed by Mugil cephalus in response to an external application of $300 \mu \mathrm{g} \mathrm{NaCN}$ into the ventilatory stream via a buccal cannula and maintained in clear water $(a)$ or in turbid water containing 300 NTU Polsperse 10 kaolin $(b)$ at a temperature of $25^{\circ} \mathrm{C}$ and salinity of $36 \%$. Open circles represent ASR events in the absence of the model predator, and solid circles represent events in the presence of the model predator. The outer lines at the top of the diagram represent a sheltered area in the aquarium. 
Table 3: Mean ( \pm SE) distances of all aquatic surface respiration (ASR) episodes from the nearest tank wall and the proportion of ASR episodes that occurred under shelter at the rear of the tank performed by Mugil cephalus

\begin{tabular}{|c|c|c|c|c|}
\hline & \multicolumn{2}{|l|}{$\mathrm{NaCN}$} & \multicolumn{2}{|l|}{ Hypoxia } \\
\hline & $\begin{array}{l}\text { ASR under Shelter at } \\
\text { Rear }(\%)\end{array}$ & $\begin{array}{l}\text { Distance from Wall } \\
(\mathrm{cm})\end{array}$ & $\begin{array}{l}\text { ASR under Shelter at } \\
\text { Rear }(\%)\end{array}$ & $\begin{array}{l}\text { Distance from Wall } \\
(\mathrm{cm})\end{array}$ \\
\hline Clear water & $14.4 \pm 5.0^{\mathrm{A}}$ & $6.2 \pm .9^{\mathrm{A}}$ & $33.7 \pm 3.8$ & $4.2 \pm .6^{\mathrm{A}}$ \\
\hline Clear + predator & $31.0 \pm 7.4^{\mathrm{B}}$ & $3.4 \pm 1.1^{\mathrm{B}}$ & $51.6 \pm 21.1$ & $1.8 \pm .1^{\mathrm{B}}$ \\
\hline Turbid water & $8.4 \pm 6.6^{\mathrm{A}}$ & $3.6 \pm .9^{\mathrm{B}}$ & $24.9 \pm 4.7$ & $2.1 \pm .3^{\mathrm{AB}}$ \\
\hline Turbid + predator & $42.2 \pm 22.0^{\mathrm{B}}$ & $4.9 \pm .4^{\mathrm{B}}$ & $15.0 \pm 8.8$ & $1.9 \pm .3^{\mathrm{AB}}$ \\
\hline
\end{tabular}

Note. Data following a bolus of $2 \mathrm{mg} \mathrm{NaCN}$ into the ventilatory stream via a buccal cannula $(\mathrm{NaCN})$ or stepwise reductions in water Po ${ }_{2}($ hypoxia). Experiments were conducted in either the absence or presence of a model bird predator passed overhead every $6 \mathrm{~s}$, either in clear water or in water containing 300 NTU Polsperse 10 kaolin (turbid). For NaCN treatments in clear water, $n=7$; for all other treatments, $n=6$. Where indicated, a different letter indicates a significant difference between the means for that variable.

chemoreceptors, which appear to be distributed diffusely throughout these organs in water-breathing fish (Burleson and Smatresk 1990a; Burleson and Milsom 1993), in fish that perform ASR (Sundin et al. 2000; Florindo et al. 2002, 2004), and in fish with bimodal respiration (McKenzie et al. 1991). This may, therefore, also be the case in the mullet. While the mullet's surfacing reflex clearly reflected stimulation of receptors, receptor drive should drop when ASR had reoxygenated ventilatory water and branchial blood. This might be the reason for cessation of the behavior and reimmersion, followed by repetition of the surfacing reflex when the immersed fish became hypoxic again. It is possible that the reflex surfacing response for ASR was an evolutionary precursor of the air-gulping responses of bimodal fish and amphibians (Smatresk et al. 1986; McKenzie et al. 1991; McKenzie and Taylor 1996) and, therefore, that the low capacitance of water for dissolved $\mathrm{O}_{2}$ and consequent frequency of hypoxia were a driving force in the evolution of the vertebrates and their colonization of land (Randall et al. 1981).

\section{Modulatory Effect of the Model Predator on $\mathrm{O}_{2}$ Chemoreflexes}

The selective pressures of predation have been ubiquitous during animal evolution. The threat of predation had significant effects on cardiac and branchial ventilatory activity in the mullet and also modulated their $\mathrm{O}_{2}$ chemoreflexes. The bradycardia and hypoventilation caused by the shadow of the model predator corresponds to a "freeze" response (Johnsson et al. 2001; Cooke et al. 2003). Given that the motor arms of these reflexes are the same as those of the cardiac and branchial chemoreflexes, it is not surprising that there was an interaction between the responses. It is very interesting, however, that the interaction differed for cardiac and branchial variables, in that the freeze bradycardia caused the chemoreflexive bradycardia to be more profound, whereas the freeze hypoventilation abolished the chemoreflexive increase in gill ventilation rate and significantly attenuated the increase in opercular pressure amplitude. The nervous networks controlling cardiac and branchial ventilatory
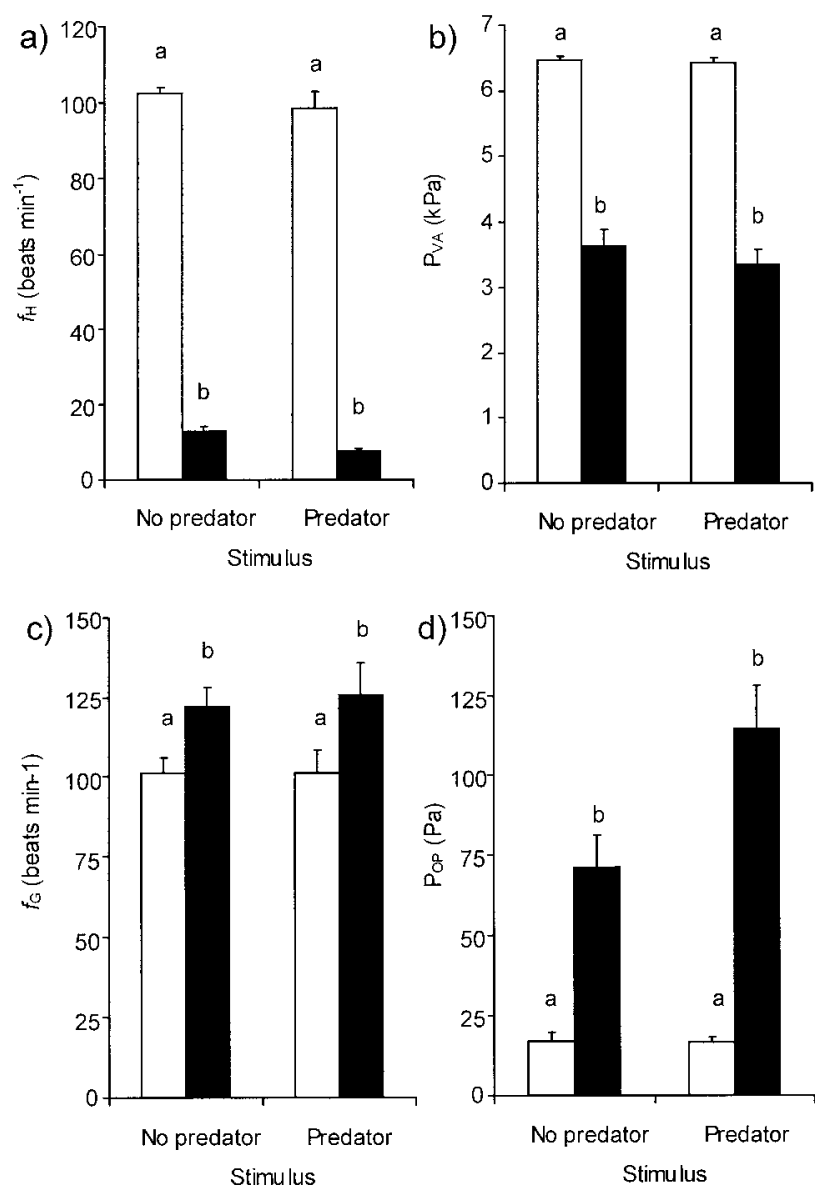

Figure 5. Effect of a model bird predator on mean $( \pm S E)$ heart rate $(a)$, blood pressure $(b)$, ventilatory frequency $(c)$, and opercular pressure amplitude $(d)$ either before (open columns) or at peak measured response after (solid columns) an external application of $2 \mathrm{mg} \mathrm{NaCN}$ into the ventilatory stream via a buccal cannula in Mugil cephalus in turbid water containing 300 NTU Polsperse 10 kaolin at a temperature of $25^{\circ} \mathrm{C}$ and salinity of $36 \%$. Where indicated, a different letter indicates a significant difference between the means for that variable. 

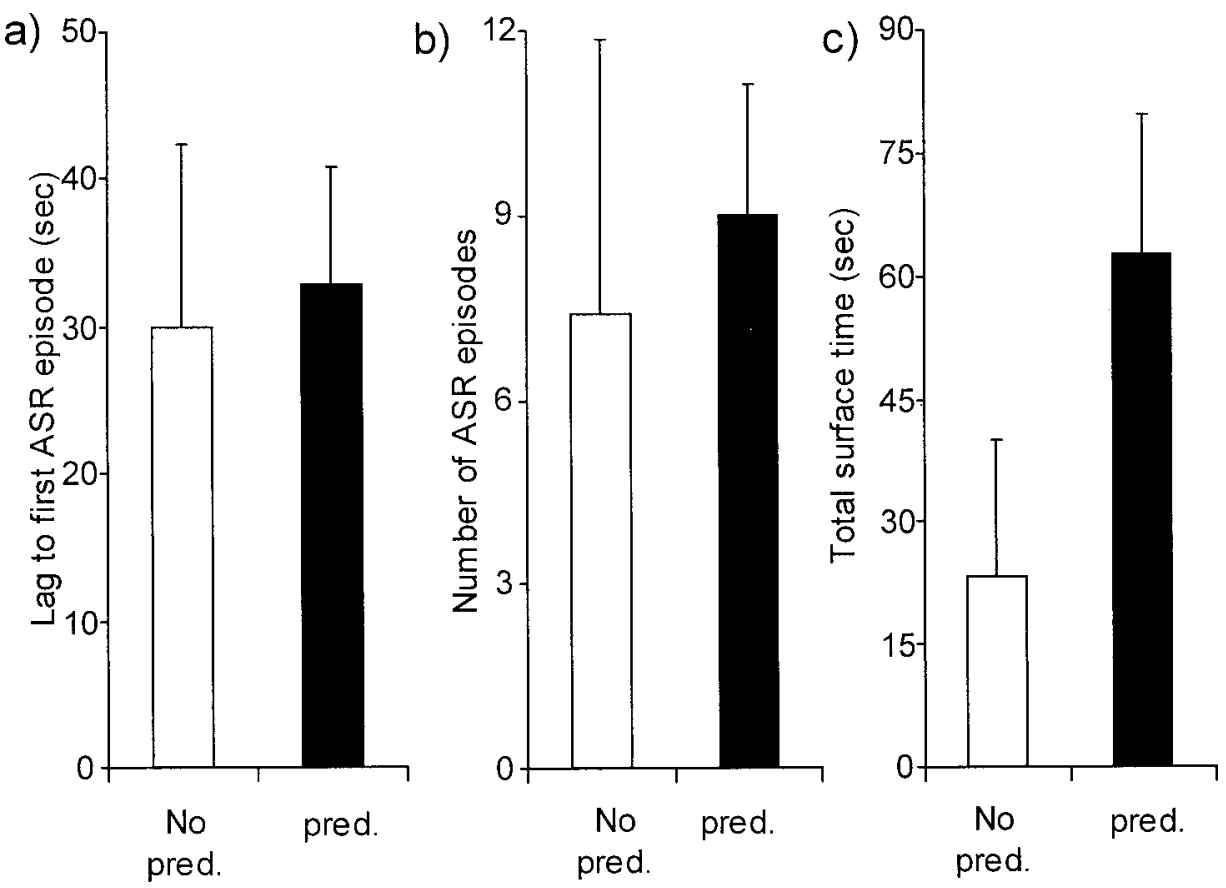

Figure 6. Effect of a model predator on mean $( \pm \mathrm{SE})$ time lag to the onset of aquatic surface respiration (ASR; $a$ ), number of ASR episodes $(b)$, and total time spent at the surface performing ASR $(c)$ following an external application of $2 \mathrm{mg} \mathrm{NaCN}$ into the ventilatory stream via a buccal cannula in Mugil cephalus in turbid water containing 300 NTU Polsperse 10 kaolin at a temperature of $25^{\circ} \mathrm{C}$ and salinity of $36 \%$.

activity in teleost fish are known to reside in the medulla (Hughes and Shelton 1962; Ballintijn 1988; Sundin et al. 2003), and this also appears to be the case for air-breathing reflexes in bimodal fish (Wilson et al. 2000), but very little is known about how reflex activity is modified by inputs from higher centers (Ballintijn and Juch 1984; Roberts and Ballintijn 1988; Taylor et al. 1999). Tracing of the sensory afferents from the gills and of the motor efferents serving the gills and heart found that these did not make contact in the medulla of the shorthorn sculpin Myoxocephalus scorpius (Sundin et al. 2003). Thus, in the mullet, higher behavioral inputs may influence cardiac and branchial chemoreflexes through interaction with medullary interneurons.

The adaptive significance of the branchial "breath-holding" response in response to the model predator is difficult to fathom; it may simply reflect an overall inhibition of skeletal musculature as the fish attempts to reduce movements and visibility (Cooke et al. 2003). It would, however, seem to be a maladaptive response, since in purely water-breathing fish it would reduce the tolerance of hypoxia, and for fish that need to perform ASR it might be expected to stimulate ASR behavior by exasperating systemic hypoxia. The final behavior shown by the fish may reflect a trade-off between avoiding detection by predators and meeting aerobic energy requirements. The breath-holding response in the mullet is in direct contrast with observations on an air-breathing fish, the Florida gar (Lepisos- teus platyrhincus), where exposure to a model predator in hypoxia inhibited surfacing frequency and caused increased gill ventilation rate (Smith and Kramer 1986).

This is the first study to show behavioral modulation of hypoxic chemoreflexes when at risk from predation, with the fish selecting areas of cover to perform ASR. This same modulation of chemoreflexes may underlie the findings by Kramer et al. (1983), whereby fish performing ASR in hypoxia tended to avoid the vicinity of a real avian predator by moving deeper in the water column and to the opposite ends of the aquarium. The qualitatively similar changes to the hypoxic ASR behavior that were observed in the noninstrumented mullet when threatened by the model predator indicate that the adaptive modulation of the reflex would also occur in hypoxic natural environments. Indeed, Kersten et al. (1991) found that when possible, mosquito fish (Gambusia affinis) performing ASR in a hypoxic marsh would move to the water's edge and take shelter under riparian vegetation when threatened by predatory egrets. In this study, some of the noninstrumented mullet did not perform ASR at all in hypoxia when threatened by the model predator. Such fish may become more vulnerable to predation if systemic effects of hypoxia impair their performance and jeopardize their chances of making a successful escape response. For example, hypoxia reduced responsiveness and left-right discrimination in a similar gray mullet species (Liza aurata) exposed to a mechanical stimulus that mimicked 
a)

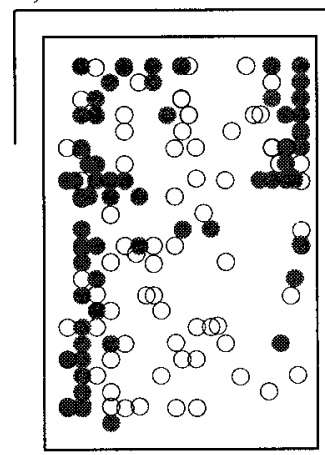

b)

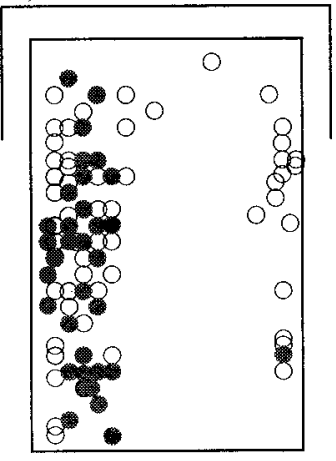

Figure 7. Aerial view of locations of ASR events performed by Mugil cephalus in response to hypoxia in clear water $(a)$ or turbid water containing 300 NTU Polsperse 10 kaolin $(b)$ at a temperature of $25^{\circ} \mathrm{C}$ and salinity of $36 \%$. Open circles represent ASR events in the absence of the model predator, and solid circles represent ASR events in the presence of a model predator. The outer lines at the top of the diagram represent a sheltered area in the aquarium.

a strike by an avian predator, and locomotor elements of the escape response were strongly impaired when access to the surface and ASR was denied (C. Lefrançois, A. Shingles, and P. Domenici, unpublished data).

\section{Modulatory Effects of Turbidity}

The fact that turbidity abolished all cardiac and branchial responses to the model predator indicates that the mullet could not see it. Turbidity is known to affect predator-prey interactions by affecting the visual range of fish (Vinyard and O'Brien 1976; Confer et al. 1978; Gardner 1981). Gregory (1988, 1993) found that reaction distance and perceived risk of predation from a model predator declined inversely with turbidity in juvenile Chinook salmon (Oncorhynchus tsawytscha) and that their evasive behavior and responses to simulated predation by model fish and bird predators were less pronounced and of shorter duration. Turbidity has also been found to have negative effects on the success of birds preying on fish within the water column (Cezilly 1992), but this may not necessarily be true if birds were preying on fish as they surfaced. It is interesting, therefore, that when stimulated by $\mathrm{NaCN}$, the mullet always performed ASR near edges or under shelter. This indicates that the turbidity itself elicited adaptive modulation of the chemoreflex to reduce the threat of predation. The modulation was not dependent on an actual perceived threat and the associated changes in cardiac and branchial activity.

\section{Conclusions and Perspectives}

The results demonstrate that ASR is a complex behavioral $\mathrm{O}_{2}$ chemoreflex that can be modulated significantly by sensory

input from higher centers. If fish reduced their use of ASR when under the risk of predation to avoid injury or mortality and the expenditure of energy during an escape response, this would also require a trade-off, such as limitations to aerobic energy available for locomotion, growth, and reproduction (Kramer 1987). Consequently, it would be an advantage to fish if they were able to continue to perform ASR. This study indicates that mullet have evolved compensatory strategies that would allow them to retain advantages of ASR while mitigating the threat of aerial predation. This was revealed as an increased use of shelter and edges, a response that mimics observations on fish under threat of predation in the wild (Kersten et al. 1991). The modulated ASR response in the mullet was not, however, dependent on awareness of a predator; it also occurred in turbid water. Taken together, the results indicate that there is much adaptive plasticity in the behavioral elements of hypoxic chemoreflexes in the mullet.

It is important to note that the more natural conditions of the field (such as variations in light levels, surface glare and rippling, water clarity and cover) might affect both the absolute level and the gradient of risk from predation (Kramer et al. 1983). Also, one might wonder what the mullet would do if there were no edges and riparian vegetation available when it became necessary to perform ASR. There is evidence that fish and amphibians exhibit modulation of their surfacing behavior in response to conspecifics, with social synchronization of breaths (Kramer and Graham 1976; Gee 1980; Baird 1983; Chapman and Chapman 1994) whereby groups surface together or in rapid succession to reduce individual risks of aerial predation. Thus, exploring the control of reflex surfacing and airbreathing responses in fish and amphibians should not be limited to only an analysis of responses under standard laboratory conditions. For the future, it is important to consider how abiotic and biotic factors might modulate surfacing reflexes and the central processes that mediate this. This study demonstrates the importance of combining physiological measurements with ecologically relevant behavioral observations.

\section{Acknowledgments}

Financial support by the European Union, Directorate Fisheries, through contract QLRS-2002-00799, Project ETHOFISH, is acknowledged. We are grateful to E. Standen for help with the model predator exposures and to Dr. M. Burrows for his advice on statistical analysis.

\section{Literature Cited}

Baird T.A. 1983. The influence of social and predatory stimuli on the air breathing of the African clawed frog Xenopus laevis (Daudin). Copeia 1983:411-420.

Ballintijn C.M. 1988. Evolution of central nervous control of 
ventilation in vertebrates. Pp. 3-27 in E.W. Taylor, ed. The Neurobiology of the Cardio-Respiratory System. Manchester University Press, Manchester.

Ballintijn C.M. and P.J.W. Juch. 1984. Interaction of respiration with coughing, feeding, vision and oculomotor control in fish. Brain Behav Evol 25:99-108.

Burleson M.L. and W.K. Milsom. 1993. Sensory receptors in the first gill arch of rainbow trout. Respir Physiol 93:97-110.

Burleson M.L. and N.J. Smatresk. 1990a. Effects of sectioning cranial nerves IX and X on cardiovascular and ventilatory reflex responses to hypoxia and $\mathrm{NaCN}$ in channel catfish. J Exp Biol 154:407-420.

- 1990b. Evidence for two oxygen-sensitive chemoreceptor loci in channel catfish, Ictalurus punctatus. Physiol Zool 63:208-221.

Burleson M.L., N.J. Smatresk, and W.K. Milsom. 1992. Afferent inputs associated with cardioventilatory control in fish. Pp. $389-426$ in W.S. Hoar, D.J. Randall, and A.P. Farrell, eds. Fish Physiology. Vol. XIIB. Academic Press, New York.

Cezilly, F. 1992. Turbidity as an ecological solution to reduce the impact of fish-eating colonial waterbirds on fish farms. Colon Waterbirds 15:249-252.

Chapman L.J. and C.A. Chapman. 1994. Observations on synchronous air breathing in Clarias liocephalus. Copeia 1994: 246-249.

Chapman L.J., L.S. Kaufman, C.A. Chapman, and F.E. McKenzie. 1994. Hypoxia tolerance in twelve species of East African cichlids: potential for low oxygen refugia in lake Victoria. Conserv Biol 9:1274-1287.

Confer J.L., G.L. Howick, M.H. Corzett, S.L. Kramer, S. Fitzgibbon, and R. Landesberg. 1978. Visual predation by planktivores. Oikos 31:27-37.

Cooke S., J. Steinmetz, J.F. Degner, E.C. Grant, and D.P. Philipp. 2003. Metabolic fright responses of different-sized largemouth bass (Micropterus salmoides) to two avian predators show variations in nonlethal energetic costs. Can J Zool 81: 699-709.

Diaz R.J. 2001. Overview of hypoxia around the world. J Environ Qual 30:275-281.

Dickson Hoese H. 1985. Jumping mullet: the internal diving bell hypothesis. Environ Biol Fishes 13:309-314.

Florindo L.H., A.L. Kalinin, and S.G. Reid. 2002. The role of orobranchial $\mathrm{O}_{2}$ chemoreceptors on the control of the aquatic surface respiration in tambaqui, Colossoma macropomum. Proceedings from the International Congress on the Biology of Fish, Vancouver.

Florindo L.H., S.G. Reid, A.L. Kalinin, W.K. Milsom, and F.T. Rantin. 2004. Cardiorespiratory reflexes and aquatic surface respiration in the Neotropical fish tambaqui (Colossoma macropomum): acute responses to hypercarbia. J Comp Physiol B 174:319-328.

Gardner M.B. 1981. Effects of turbidity on feeding rates and selectivity of bluegills. Trans Am Fish Soc 110:446-450.
Gee J.H. 1980. Respiratory patterns and antipredator responses in the central mudminnow, Umbra limi, a continuous, facultative, air-breathing fish. Can J Zool 58:819-827.

Gee J.H. and P.A. Gee. 1991. Reaction of gobioid fishes to hypoxia: bouyancy control and aquatic surface respiration. Copeia 1991:17-28.

Gee J.H., R.F. Tallman, and H.J. Smart. 1978. Reactions of some great plains fishes to progressive hypoxia. Can J Zool 56: 1962-1966.

Gregory R.S. 1988. Effects of turbidity on benthic foraging and predation risk in juvenile Chinook salmon. Pp. 65-73 in C.A. Simenstad, ed. Effects of Dredging on Anadromous Pacific Coast Fishes. Workshop Proceedings, September 8-9, 1988. Washington Sea Grant Program, University of Washington, Seattle.

1993. The effect of turbidity on the predator avoidance behaviour of juvenile Chinook salmon (Oncorhynchus tshaw$y t s c h a$ ) in turbid laboratory conditions. Can J Fish Aquat Sci 50:241-246.

Gregory R.S. and T.G. Northcote. 1993. Surface, planctonic, and benthic foraging by juvenile Chinook salmon (Oncorhynchus tshawytscha) in turbid laboratory conditions. Can J Fish Aquat Sci 50:233-240.

Herbert N.A. and R.M.G. Wells. 2001. The aerobic physiology of the air-breathing blue gourami, Trichogaster trichopterus, necessitates behavioural regulation of breath-hold limits during hypoxic stress and predatory challenge. J Comp Physiol B 171:603-612.

Hughes G.M. and G. Shelton. 1962. Respiratory mechanisms and their nervous control in fish. Adv Comp Physiol Biochem 1:275-364.

Johnsson J.I., J. Höjesjo, and I.A. Flemming. 2001. Behavioural and heart rate responses to predation risk in wild and domesticated Atlantic salmon. Can J Fish Aquat Sci 58:788794.

Kersten M., R.H. Britton, P.J. Dugan, and H. Hafner. 1991. Flock feeding and food intake in little egrets: the effects of prey distribution and behaviour. J Anim Ecol 60:241-252.

Kramer D.L. 1987. Dissolved oxygen and fish behaviour. Environ Biol Fishes 18:81-92.

Kramer D.L. and J.B. Graham. 1976. Synchronous air breathing, a social component of respiration in fishes. Copeia 1976: 689-697.

Kramer D.L., D. Manley, and R. Bourgeois. 1983. The effect of respiratory mode and oxygen concentration on the risk of aerial predation in fishes. Can J Fish Aquat Sci 61:653-665.

Kramer D.L. and M. McClure. 1982. Aquatic surface respiration, a widespread adaptation to hypoxia in tropical freshwater fishes. Environ Biol Fishes 7:47-55.

Lewis W.M. 1970. Morphological adaptations of cyprinodontoids for inhabiting oxygen deficient waters. Copeia 2:319326.

McKenzie D.J., M.L. Burleson, and D.J. Randall. 1991. The 
effects of branchial denervation and pseudobranch ablation on cardioventilatory control in an air-breathing fish. J Exp Biol 161:347-365.

McKenzie D.J., G. Piraccini, A. Felskie, P. Romano, C.L. Bolis, and P. Bronzi. 1999. Effects of plasma total ammonia content and $\mathrm{pH}$ on urea excretion in Nile tilapia. Physiol Biochem Zool 72:116-126.

McKenzie D.J. and E.W. Taylor. 1996. Cardioventilatory responses to hypoxia and $\mathrm{NaCN}$ in the neotenous axolotl. Respir Physiol 106:255-262.

McKenzie D.J., E.W. Taylor, P. Bronzi, and L. Bolis. 1995. Aspects of cardioventilatory control in the Adriatic sturgeon (Acipenser naccarii). Respir Physiol 100:44-52.

Randall D.J., W.W. Burggren, A.P. Farrell, and M.S. Haswell. 1981. The Evolution of Air Breathing in Vertebrates. Cambridge University Press, Cambridge.

Roberts B.L. and C.M. Ballintijn. 1988. Sensory interaction with central generators during respiration in dogfish. J Comp Physiol A 162:695-704.

Smatresk N.J. 1990. Chemoreceptor modulation of the endogenous respiratory rhythm in vertebrates. Am J Physiol 259: R887-R897.

Smatresk N.J., M.L. Burleson, and S.Q. Azizi. 1986. Chemoreflexive responses to hypoxia and $\mathrm{NaCN}$ in longnose gar: evidence for two chemoreceptive loci. Am J Physiol 251: R116-R125.
Smith R.S. and D.L. Kramer. 1986. The effect of apparent predation risk on the respiratory behaviour of the Florda gar (Lepisosteus platyrhincus). Can J Zool 64:2133-2136.

Sundin L., S.G. Reid, F.T. Rantin, and W.K. Milsom. 2000. Branchial receptors and cardiorespiratory reflexes in a Neotropical fish, the tambaqui (Colossoma macropomum). J Exp Biol 203:1225-1239.

Sundin L., J. Turesson, and E.W. Taylor. 2003. Evidence for glutamatergic mechanisms in the vagal sensory pathway initiating cardiorespiratory reflexes in the shorthorn sculpin Myoxocephalus scorpius. J Exp Biol 306:867-876.

Taylor E.W., D. Jordan, and J.H. Coote. 1999. Central control of the cardiovascular and respiratory systems and their interactions in vertebrates. Physiol Rev 72:789-824.

Taylor E.W., D.J. McKenzie, J.J. Levings, and D.J. Randall. 1996. Control of ventilation in air-breathing fish. Pp. 155-168 in A.L. Val, V.M.F. Almeida-Val, and D.J. Randall, eds. Physiology and Biochemistry of Fishes of the Amazon. INPAS, Manaus.

Vinyard G.L. and W.J. O’Brien. 1976. Effects of light and turbidity on the reaction distance of bluegill (Lepomis macrochirus). J Fish Res Board Can 33:2845-2849.

Wilson R.J.A., M.B. Harris, J.E. Remmers, and S.F. Perry. 2000. Evolution of air-breathing and central $\mathrm{CO}_{2} / \mathrm{pH}$ respiratory chemosensitivity: new insights from an old fish. J Exp Biol 203:3505-3512. 